\title{
High Level of Hyaluronic Acid
}

National Cancer Institute

\section{Source}

National Cancer Institute. High Level of Hyaluronic Acid. NCI Thesaurus. Code C158675.

A finding indicating high concentrations of hyaluronic acid in a sample. 